\title{
Portland-pulverized fuel ash concretes: water demand, 28 day strength, mix design and strength development
}

\author{
D. W. Hobbs
}

Mr H. T. Cao, Division of Building Construction and Engineering, CSIRO, Australia

Dr Hobbs's Paper presents a very promising aspect of measuring potential performance of a fly ash in concrete by way of the cement replacement factor. The idea is very appealing since this factor has the potential of being used for characterization of fly ash or any other mineral additives. There are, however, some points arising from this Paper that need further discussion.

34. The fly ashes used in Dr Hobbs's work show significant variations in both densities and particle size distributions (Table 2). As a consequence of these variations, the mix proportions must have been adjusted when different fly ashes were used to correct the concrete yield. The measured slump would be governed by the adopted volumetric proportions of mix constituents. The parity of slump based on different mix proportions is not entirely applicable. Information with regard to details of the mix proportions used in the Paper would clarify this point.

35. Table 3 and Fig. 2 of the Paper show that there was a significant scattering of results of the cementing efficiency factor. In the case of OPC 4, pfa 3 , the average value of the cementing efficiency factor seems to be about 0.4 . The dependency of the cementing efficiency factor on the particular combination of OPC and fy ash and on the cement replacement percentage found in the Paper appears to indicate strongly the unique interaction between OPC and fly ash in a given blend.

36. It is shown clearly in the Paper that, at a particular cement replacement percentage, the behaviour of blended cements is quite different from that of plain $O P C$. This is reflected through strength development and water demand in the fresh concrete mix.

37. In view of this, doubt must be cast on the approach of averaging certain experimentally determined parameters, such as binder content and water-cement ratio, to achieve parity of strength and slump of OPC concrete for a range of different OPC and fly ash blends, and of using these average properties in the mix design of other fly ash blends.

38. The variations exhibited by different fly ashes indicate that a fly ash blended cement should be looked on as a different type of cement with its own characteristics. The concepts of cementing efficiency factor and cement replacement factor, at a given strength and slump level, are better used as parameters to characterize or classify a range of fly ash blended cements.

39. Comments from the Author with regard to this approach to characterization of fly ash/OPC blends would be much appreciated.

Paper published: Proc. Instn Civ. Engrs, Part 2, 1988, 85, June, 317-331. 


\section{DISCUSSION}

Mr W. B. Butler, Amatek (Australian Materials \& Technology), Construction Materials Division, Villawood

This work makes a substantial contribution to the available data on the performance of pfa which complies with BS 3892, Part $1 .^{2}$

41. Dr Hobbs has--I believe for the first time-drawn attention to the difference between the way Smith $^{6}$ described his $k$ factor (which equates to Hobbs's cement replacement factor $\left.\left(c_{1}-c_{2}\right) / p\right)$ and the way he calculated it, i.e. $w_{1} / c_{1}=$ $w_{2} /\left(c_{2}+k p\right)$. I am sure that this difference has caused confusion in the past and will continue to do so for those who have not read this Paper.

42. A further valid conclusion which can be drawn from Table 6 of the Paper is that the early strength of concrete containing pfa is less adversely affected by lowering the casting temperature than that of OPC concrete. Not many of us would have expected this. In fact, concrete containing pfa need not be at any disadvantage with early strength, even when the concrete is not water-cured, provided that a water-reducing admixture is used (Table 9). Data on $30 \mathrm{MPa}$ concrete ${ }^{16}$ are indicative.

43. In $\S 5$, Dr Hobbs states: "If pfa is added to a concrete mix without any other changes being made then the workability will be reduced on account of the increased viscous drag provided by the increased volume of solids.' Dr Helmuth makes similar comments in his excellent book $F l y$ ash in cement and concrete. ${ }^{17}$ However, even with the OPC content held constant, if pfa is added and compensation is made for yield, by adjusting the fine aggregate content, the workability will be increased for pfa complying with BS 3892, Part 1.

44. Typical data to support this statement are provided by concretes mixed using Great Ouse Valley aggregate with Rugby Barrington cement and Monier HPFA from West Burton P.S. For these mixes, slump increased, in spite of the reduction in free water content (see Table 10).

45. In addition to the size, shape and volume effects mentioned by Dr Hobbs, Helmuth ${ }^{17}$ suggests that an adsorption and dispersion process, similar to organic water-reducing admixtures, may contribute.

46. Perhaps the greatest advantage of separate addition of pfa to a concrete mix is the ability to modify the proportions of OPC and pfa. The optimum proportion of pfa typically reduces ${ }^{18}$ as the strength level increases. Hence it is unfortunate that the Department of the Environment method of mix design ${ }^{10}$ leads the user into proportioning pfa as a percentage of total binder. The pfa concrete mixes developed in Tables 4 and 5 show pfa content increasing with cement when, in each case, the concrete produced would probably be improved if the order of the data in the column for $p$ were reversed so that less pfa was used as the cement content increased.

Table 9. Strength development of air-stored specimens as a percentage of 28 day water-cured specimens

\begin{tabular}{l|c|c|c}
\hline \multirow{2}{*}{ Mixture type } & \multicolumn{2}{|c|}{ Compression tests } & Flexure tests \\
\cline { 2 - 4 } & 3 days & 7 days & 7 days \\
\hline OPC concrete & 48 & 57 & 65 \\
OPC/water-reducing admixture & 51 & 72 & 68 \\
OPC/pfa/water-reducing admixture & 47 & 63 & 68 \\
\hline
\end{tabular}




\begin{tabular}{l|c|c|c}
\hline & \multicolumn{3}{|c}{ Proportions: kg/m $\mathrm{m}^{3}$} \\
\hline Mix no. & $7 \mathrm{a}$ & $8 \mathrm{a}$ & $9 \mathrm{a}$ \\
Cement & 294 & 297 & 297 \\
pfa & 0 & 50 & 75 \\
Stone & 1191 & 1202 & 1203 \\
Sand & 732 & 686 & 661 \\
Water & 171 & 164 & 160 \\
Slump:mm & 50 & 65 & 70 \\
\hline
\end{tabular}

47. Table 4 and the conclusion both suggest that the cement replacement factor reduces as the cement content increases, while Table 5 assumes that it remains constant. In our experience, neither is the case with properly designed mixes. In data reproduced in Figs 12 and 13 from a paper presented in July 1988, ${ }^{19}$ the "fly ash activity factor $k$ equates to the cement replacement factor used by $\mathrm{Dr}$ Hobbs. The factor decreases as the addition rate of pfa increases, but, in each case, when the data are examined on the basis of pfa content held constant, the factor increases as the strength (and cement content) increases.

48. Although the results shown are for concretes containing water-reducing admixtures, similar results are available for UK pfa without admixtures. However, if the data are processed on the basis of pfa as a fixed proportion of total binder, the cement replacement factor may diminish as strength increases, as it should with departures from optimum conditions. The class of pfa (in terms of ASTM) and the pfa proportion will significantly influence the result. Dr Hobbs's data are not in question, just the basis of presentation.

49. Design of normal concrete mixes ${ }^{10}$ depends on the assumption that for pfa there will be a $3 \%$ water reduction for every $10 \%$ pfa in the binder. This assumption was built into Table 8 of Dr Hobbs's Paper and may not be valid. From sets of data we have been able to study so far, the following conclusions are indicated.

(a) For a given set of materials, at fixed slump, free water requirement varies across the strength range.

(b) Both the magnitude of the water requirement and the shape of the curve (water against strength) are influenced by the actual cement and aggregates used. Some materials require less water as the cement content increases; most require more.

(c) With mixes containing pfa, the variation in water requirement with strength level (at constant pfa by mass) is much less than for OPC mixes.

(d) As the pfa content increases, the water requirement normally reduces but can change direction when the total binder level is high.

(e) The water requirement curves for cement/pfa mixes do not seem to relate to the water requirement curve of the parent cement/aggregate combination. Hence the water reduction values can be quite misleading.

50. The real problem area in the method, which is common to most methods of concrete mix design, is the assumption that free water requirement is essentially constant for normal mixes. We have recorded differences in water content of 
DISCUSSION

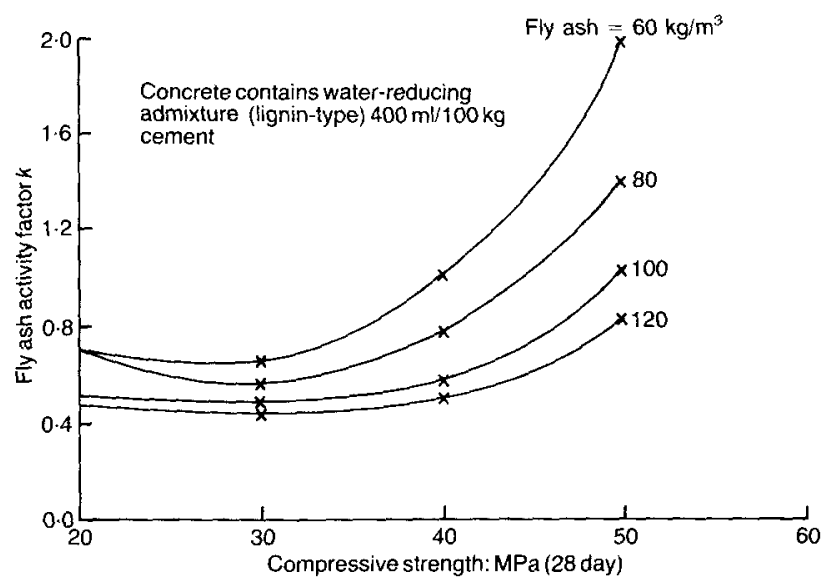

Fig. 12. Commercial fly ash (NSW Class F): strength against $k$ factor

$15 \mathrm{~kg} / \mathrm{m}^{3}$, or more, just by changing cement source. When these same cements are used with pfa, the water requirements are similar but the water reductions are not. The solution may be to predict the actual water content for pfa mixes on the basis of the mass of pfa used, rather than to predict the reductions in water content resulting from various proportions of pfa in the binder.

\section{Dr Hobbs}

Table 11 gives a number of the mix proportions for OPC concretes and concretes containing $30 \%$ or $35 \%$ pfa, which were of similar slump and similar 28 day strength.

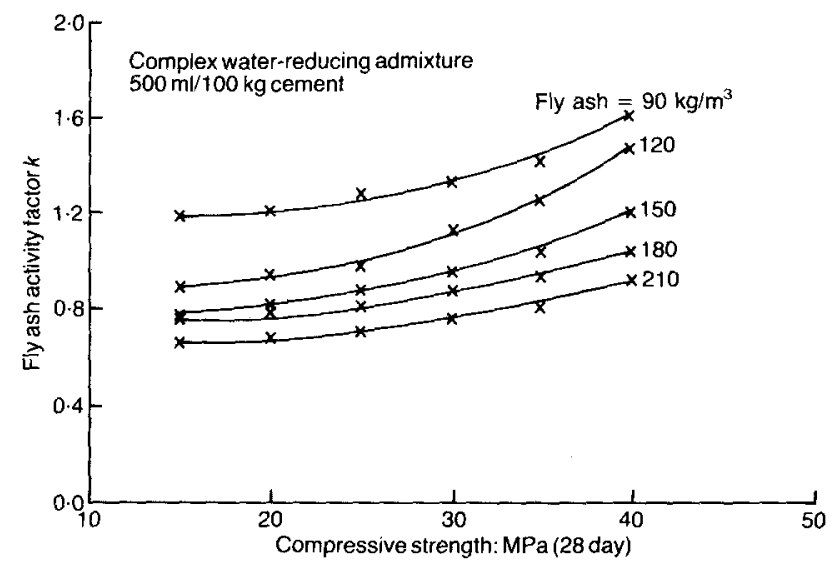

Fig. 13. High lime (Class C) fly ash from sub-bituminous coal (USA): strength against $k$ factor 
Table 11. Mix proportions in $\mathrm{kg} / \mathrm{m}^{3}$ for OPC concretes and concretes containing $30 \%$ or $35 \%$ pfa which are of similar slump and similar 28 day strength

\begin{tabular}{c|c|c|c|c|c}
\hline \multirow{2}{*}{$\begin{array}{c}\text { OPC/pfa } \\
\text { combination }\end{array}$} & \multicolumn{2}{|c|}{ OPC concretes } & \multicolumn{3}{c}{ OPC-pfa concretes } \\
\cline { 2 - 6 } & $c_{1}$ & $w_{1}$ & $c_{2}$ & $p$ & $w_{2}$ \\
\hline \multirow{3}{*}{$1 / 1$} & 376 & 174 & 260 & 140 & 157 \\
$2 / 2$ & 278 & 180 & 213 & 115 & 160 \\
& 476 & 175 & 423 & 228 & 176 \\
& 367 & 175 & 290 & 156 & 158 \\
$3 / 4$ & 278 & 181 & 220 & 118 & 160 \\
& 475 & 190 & 453 & 194 & 195 \\
& 380 & 190 & 299 & 128 & 177 \\
& 317 & 190 & 237 & 102 & 169 \\
& 271 & 190 & 207 & 89 & 171 \\
& 238 & 190 & 180 & 78 & 167 \\
\hline
\end{tabular}

52. $\mathrm{Mr}$ Cao draws attention to the fact that the cementing efficiency factor for strength depends on the particular combination of OPC and pfa used and the percentage of OPC replaced. It is important to note, however, that water demand also depends on the particular combination of OPC and pfa used. Variations in water demand can result in similar variations to the calculated mix proportions as variations in the cementing efficiency factor. This is illustrated in Table 12.

53. Some doubts are expressed by $\mathrm{Mr}$ Cao about the value of using average properties in mix design for pfa blends where no appropriate data exist. In my view, the data and conclusions in my Paper should be taken to be broadly applicable only to UK OPC-BS 3892: Part $1^{2}$ pfa's. If no appropriate data exist for the chosen OPC-pfa combination, then the use of 'average properties' in the design of the initial trial mix is more likely to produce a mix complying with the specification than the use of 'non-average properties'.

54. Mr Butler makes the point that replacing fine aggregate by pfa can increase workability. This is so if less than about $5 \%$ of mass of the total aggregate is replaced. The reason for the increased workability is not that the addition of pfa increases workability but that the increase in workability produced by the reduction in aggregate volume concentration is greater than the reduction produced by the addition of pfa. ${ }^{12,15}$ At higher aggregate replacement levels, the work-

Table 12. Equivalent mixes: $30 \%$ pfa

\begin{tabular}{c|c|c|c|c|c|c|c}
\hline \multicolumn{2}{c|}{ OPC concretes } & \multicolumn{6}{|c}{ Equivalent Portland-pfa concretes } \\
\hline$c_{1}$ & $w_{1} / c_{1}$ & $\begin{array}{c}\text { Cementing } \\
\text { efficiency } \\
\text { factor }\end{array}$ & $\begin{array}{c}\text { Water } \\
\text { reduction: } \\
\%\end{array}$ & $c_{2}$ & $p$ & $c_{2}+p$ & $w_{2} /\left(c_{2}+p\right)$ \\
\hline 300 & 0.60 & 0.2 & 6 & 260 & 111 & 371 & 0.46 \\
& & 0.2 & 12 & 243 & 104 & 347 & 0.46 \\
& & 0.4 & 6 & 241 & 103 & 344 & 0.49 \\
& 0.4 & 12 & 225 & 96 & 321 & 0.49 \\
\hline
\end{tabular}




\section{DISCUSSION}

ability is observed to decline because the increase in workability produced by the reduction in aggregate volume concentration is now less than the reduction in workability produced by the addition of pfa. My personal view is that ' an adsorption and dispersion process' is of little significance. ${ }^{4,5}$

55. Mr Butler suggests that the greatest advantage of separate additions of pfa to a concrete mix is the ability to modify the proportions of OPC and pfa. This is true but separate additions of pfa carries a greater risk of error in the proportioning of the pfa within the binder.

56. I agree with $\mathrm{Mr}$ Butler that with increasing binder content, the concrete produced would probably be improved if less pfa were used as the cement content was increased. However, in the UK this procedure is rarely adopted: a cement replacement level of about $30 \%$ is normally used irrespective of the binder content. For such mixes, the cement replacement factor decreases with increased concrete strength.

57. The assumption made in the Department of the Environment (DoE) method of mix design, to which Mr Butler refers in $\S 46$, that there will be a $3 \%$ water reduction for every $10 \% \mathrm{pfa}$ in the binder is an approximation for mixes of normal binder content and was made to simplify the design of the initial trial mix. If more appropriate data exist for the OPC-pfa combination to be used, then the DoE method advises that these data should be incorporated into the mix design procedure. In my Paper, I showed that the reduction in water demand resulting from the use of pfa declines with increasing strength (Mr Butler's conclusion $(a)$ in $\$ 49$ ). If I had made allowance in Table 8 for this decline then the cement replacement factors for higher strength mixes would have been reduced.

58. From the data he has studied, Mr Butler has arrived at a number of conclusions, which he lists in $\S 49$, regarding the dependence of free water requirement on a number of parameters. In general, I agree with conclusions $(a),(b)$ and $(d)$, but I do not agree with conclusion (e). Conclusions $(a)$ and $(d)$ are in agreement with the results reported in my Paper. In the case of conclusion (c), I have insuffi-

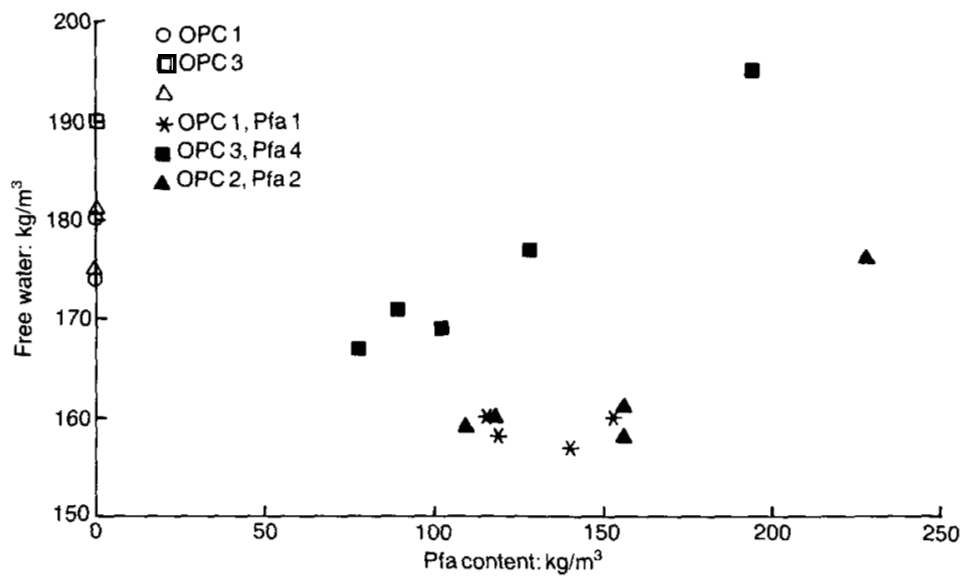

Fig. 14. Relationship between free-water content and pfa content for constant slump and 28 day strength 
cient relevant data to establish its validity for UK OPC-BS 3892: Part 1 combinations. In the case of conclusion $(e)$, we have found that within the binder range $275-400 \mathrm{~kg} / \mathrm{m}^{3}$, the partial replacement of an OPC by pfa reduces the water requirement to give an equal slump by $2-4 \%$ for each $10 \%$ pfa in the binder, irrespective of the parent cement/aggregate combination.

59. Finally, Mr Butler suggests that it may be better to predict the actual water content for pfa mixes on the basis of the mass of pfa used. Fig. 14 shows this relationship for some of the data I have obtained. I believe that Mr Butler's proposal is worthy of further study, but on the basis of Fig. 14 it does not look too promising.

\section{References}

16. BUtLER W. B. and ASHBY J. B. The influence of curing environment upon the properties of concrete made using a variety of Portland cement supplements. Proc. Conf. on Technology of Concrete When Pozzolans, Slags and Chemical Admixtures are Used. ACI-RILEM, Monterrey, Mexico, 1985.

17. Helmuth R. Fly ash in cement and concrete. Portland Cement Association, Skokie, Illinois, 1987.

18. BUTLER W. B. Economical binder proportioning with cement-replacement materials. Cement, Concrete and Aggregates, CCAGDP, 1988, 10, No. 1, 45-47.

19. Butler W. B. (RYAN W. G. (ed.)) Fly ash and fly ash concrete in England, USA and Australia. Concrete Workshop 88, Sydney, July 1988, 131-158. 